\title{
Corrigendum: A palaeoenvironmental interpretation of the Silurian rocks in the Pentland Hills, near Edinburgh, Scotland
}

[Transactions of the Royal Society of Edinburgh: Earth Sciences 80 (1989), 127-141]

\author{
Gary Robertson
}

On page 128 , left-hand column of text, lines 12,13 and 14 should read:

'The "Gutterford Burn Limestone" is not really a limestone as Henderson (1880) described, but rather a highly fossiliferous, hence calcareous, siltstone.'

GARY ROBERTSON, Mobil North Sea Ltd, Mobil Court, 3 Clements Inn, London WC2, U.K. 